Check for updates

Cite this: Chem. Commun., 2022, 58,3027

Received 22nd January 2022,

Accepted 3rd February 2022

DOI: $10.1039 / d 2 c c 00446 a$

rsc.li/chemcomm

\section{Titanium isopropoxide-mediated cis-selective synthesis of 3,4-substituted butyrolactones from $\mathrm{CO}_{2} \dagger$}

\author{
Aleksi Sahari, (D) ${ }^{a}$ Cuong Dat Do, (D) ${ }^{b}$ Jere K. Mannisto, (D) ${ }^{a}$ Emanuele Antico, (D) ${ }^{a}$ \\ Angelo Amaratunga, (D) ${ }^{a}$ Kathrin H. Hopmann (D) *c and Timo Repo (D) *a
}

\begin{abstract}
We report a $\mathrm{Ti}(\mathrm{OiPr})_{4}$-mediated multicomponent reaction, which produces 3,4-substituted $c i s$ - $\delta$-lactones from alkyl magnesium chloride, benzaldehyde and $\mathrm{CO}_{2}$. The key intermediate, titanacyclopropane, is formed in situ from $\mathrm{Ti}(\mathrm{OiPr})_{4}$ and a Grignard reagent, which enables 1,2-dinucleophilic reactivity that is used to insert carbon dioxide and an aldehyde. An alternative reaction route is also described where a primary alkene is used to create the titanacyclopropane. A computational analysis of the elementary steps shows that the carbon dioxide and the aldehyde insertion proceeds through an inner-sphere mechanism. A variety of cisbutyrolactones can be synthesized with up to $7: 1$ diastereoselectivity and $77 \%$ yield.
\end{abstract}

Carbon dioxide is a greenhouse gas and a renewable, non-toxic and inexpensive C1-source; therefore, its utilization in chemical synthesis is desirable. Typically, organometallic species are necessary to generate $\mathrm{C}-\mathrm{CO}_{2}$ bonds. ${ }^{1}$ Grignard reagents and organolithium reagents are well known to react as nucleophiles towards $\mathrm{CO}_{2}$ to form the corresponding metal carboxylates. ${ }^{2}$ In this context, we envisioned organotitanium chemistry to provide an opportunity for alternative reactivity with $\mathrm{CO}_{2}$. Titanium(Iv)alkoxides mediate reductive elimination of Grignard and alkyl lithium reagents to form highly reactive titanacyclopropanes (Scheme 1A). These species have been employed in the synthesis of cyclopropanols and cyclopropyl amines in the Kulinkovich reaction (Scheme 1B). ${ }^{3}$ There, the 1,2-dinucleophilic titanacyclopropane reacts with the formally dielectrophilic ester or amide in two consequent steps. Electrophiles other than esters and amides are also reactive towards

\footnotetext{
${ }^{a}$ Department of Chemistry, University of Helsinki, FI-00014 University of Helsinki, Finland. E-mail: timo.repo@helsinki.fi

${ }^{b}$ Hylleraas Center for Quantum Molecular Sciences, Department of Chemistry, UiT The Arctic University of Norway, 9037 Tromsø, Norway

${ }^{c}$ Department of Chemistry, UiT The Arctic University of Norway, 9037 Tromsø, Norway. E-mail: kathrin.hopmann@uit.no

$\dagger$ Electronic supplementary information (ESI) available. See DOI: 10.1039/d2cc00446a
}

the titanacyclopropane ring: $\mathrm{CO}_{2}, \mathrm{I}_{2}, \mathrm{H}_{2} \mathrm{O}$ and a variety of organic electrophiles can readily insert into the $\mathrm{Ti}-\mathrm{C}$ bond. ${ }^{3 a, 4}$

However, in most of these applications, the dinucleophilic nature of the titanacyclopropane is not completely utilized and the second $\mathrm{Ti}-\mathrm{C}$ bond is usually quenched with acid, ${ }^{5}$ rather than using it to insert another functionality.

Rassadin and Six demonstrated that the insertion of $\mathrm{CO}_{2}$ into titanacyclopropane results in a five-membered titanalactone (Scheme 1C), which does not react with another $\mathrm{CO}_{2}$ molecule. ${ }^{4 c}$ The remaining $\mathrm{Ti}-\mathrm{C}$ bond can be cleaved with water or by $\mathrm{I}_{2}$, NBS or $\mathrm{O}_{2}$ to yield $\beta$-substituted carboxylic acids.

We predicted that a carbon electrophile may be able to insert into the titanalactone ring (Scheme 1D). This would generate two carbon-carbon bonds from cheap and simple starting materials, providing a useful method to rapidly increase complexity starting from simple materials. Similar insertions have been observed with titanium(II)-alkyne complexes, ${ }^{6}$ but there are limited examples for corresponding titanium(II)alkene complexes. Previously Eisch et al. had reported a

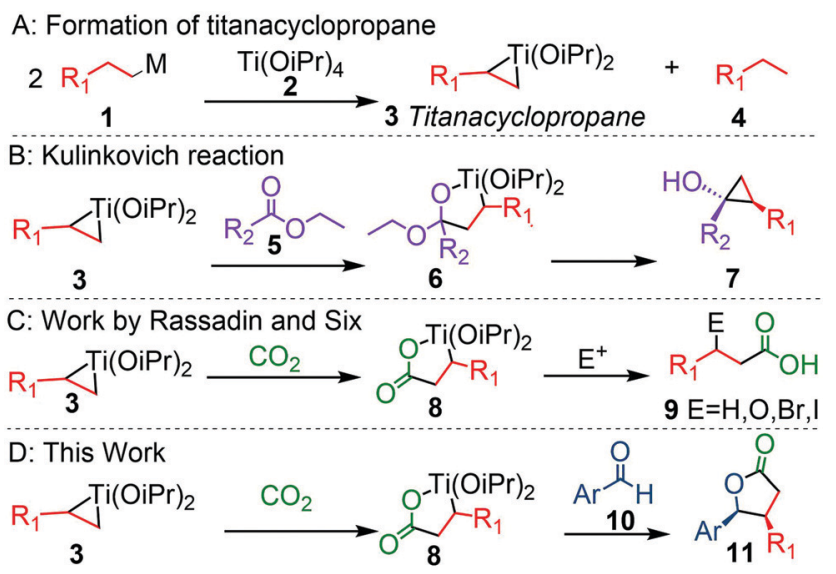

Scheme 1 Key examples of titanacyclopropane reactivity. ${ }^{3 a, 4 c}$ 
Table 1 Reaction optimization using butyl lithium ${ }^{a}$

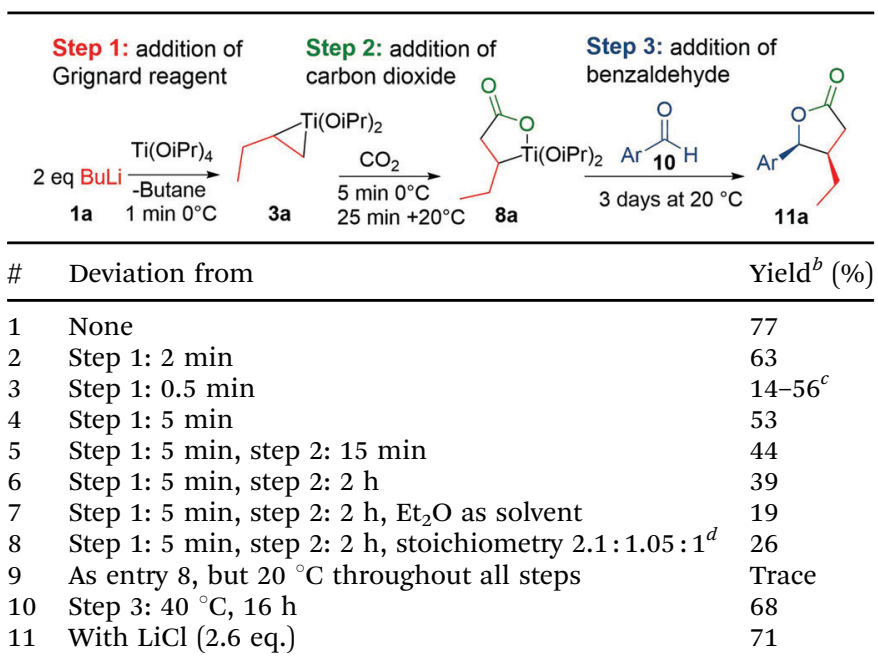

${ }^{a}$ Optimized conditions: $2.6 \mathrm{mmol} \mathrm{BuLi}, 1.3 \mathrm{mmol} \mathrm{Ti}(\mathrm{OiPr})_{4}, 1 \mathrm{mmol}$ $p$-fluorobenzaldehyde, $3 \mathrm{ml}$ of THF. Step 1: 1 min at $0{ }^{\circ} \mathrm{C}$, step 2: $5 \mathrm{~min}$ $\mathrm{CO}_{2}$ flush at $0{ }^{\circ} \mathrm{C}$ followed by $25 \mathrm{~min}$ at $20{ }^{\circ} \mathrm{C}$. Step 3 reaction time 3 days at $20{ }^{\circ} \mathrm{C} .{ }^{b}$ Entries 1 and 2 are NMR yield and entries $3-10$ are calibrated GC yield. ${ }^{c}$ Irreproducible results. ${ }^{d}$ Ratio of BuLi : Ti(OiPr) $)_{4}$ : $p$-fluorobenzaldehyde.

three- component reaction of ethene, phenyl nitrile and $\mathrm{CO}_{2}$ with preformed $\mathrm{Ti}(\mathrm{OiPr})_{2},{ }^{7}$ but its reactivity was not further explored.

Initially, we used butyl lithium to form the titanacyclopropane, which was reacted sequentially with $\mathrm{CO}_{2}$ and $p$-fluorobenzaldehyde. After optimization (Table 1), up to $77 \%$ yield of cis-lactone could be obtained, in addition to $11 \%$ of trans-lactone. The generated titanacyclopropane seems to decompose quickly under these reaction conditions. Therefore it was critical to have precise control of temperature and duration of each step. Under non-optimized conditions, titanium-derived decomposition products can further react with the aldehyde to produce a myriad of unwanted side products via for example pinacol coupling or McMurry reaction.

After proving the feasibility of the reaction using butyl lithium, we proceeded to study the reactivity with Grignard reagents, since they have better availability and are more convenient to make. When butyl magnesium chloride was used to make the titanacyclopropane, its decomposition seemed to be faster compared to the one generated from butyl lithium. The temperature for step 1 was therefore reduced from $0{ }^{\circ} \mathrm{C}$ to $-20{ }^{\circ} \mathrm{C}$ and 2.6 eq. of $\mathrm{LiCl}$ was added. With these modifications, $73 \%$ yield of $c i s$-lactone could be obtained. The effect of lithium chloride was investigated by adding a solution of LiCl in THF to the mixture right before each step (see Table S5, ESI $\dagger$ ). LiCl greatly improves the reaction yield when added before step 1 (from $31 \%$ to $65 \%$ yield) but has almost no effect when added after step 1 . LiCl is known to break up polymeric aggregates of Grignard reagents by forming $\mathrm{RMgCl} \cdot \mathrm{LiCl}$ complexes, which can increase the kinetic reactivity. ${ }^{8} \mathrm{LiCl}$ had no significant effect on the reaction involving BuLi (Table 1, entry 11), which would further suggest that its only function is to increase the reactivity of the Grignard reagent.
We also evaluated the scope of Grignard reagents (Scheme 2). Simple Grignard reagents worked well, but many functionalities were unstable under the reaction conditions. For example, ether substituents undergo elimination and do not yield any product (see Fig. S1, ESI $\dagger$ ). Secondary Grignard reagents, such as isopropyl and $\mathrm{c}-\mathrm{HexMgCl}$, only gave direct addition products to $\mathrm{CO}_{2}$ or aldehyde. Since the formation of the titanacyclopropane is a critical step in the reaction, further improvements could likely be obtained by individually optimizing the conditions for each Grignard reagent.

Next, we studied different electrophiles in step 3 in a reaction based on BuMgCl. Various benzaldehydes and $\alpha, \beta$ unsaturated cinnamaldehyde provided the desired lactone (Scheme 2). Among the tested substrates, epoxides, imines, nitriles, ketones and aliphatic aldehydes were non-reactive (Fig. S2 and S3, ESI $\dagger$ ). The more reactive acrolein and iminiums only formed various side products, which were not further analyzed.

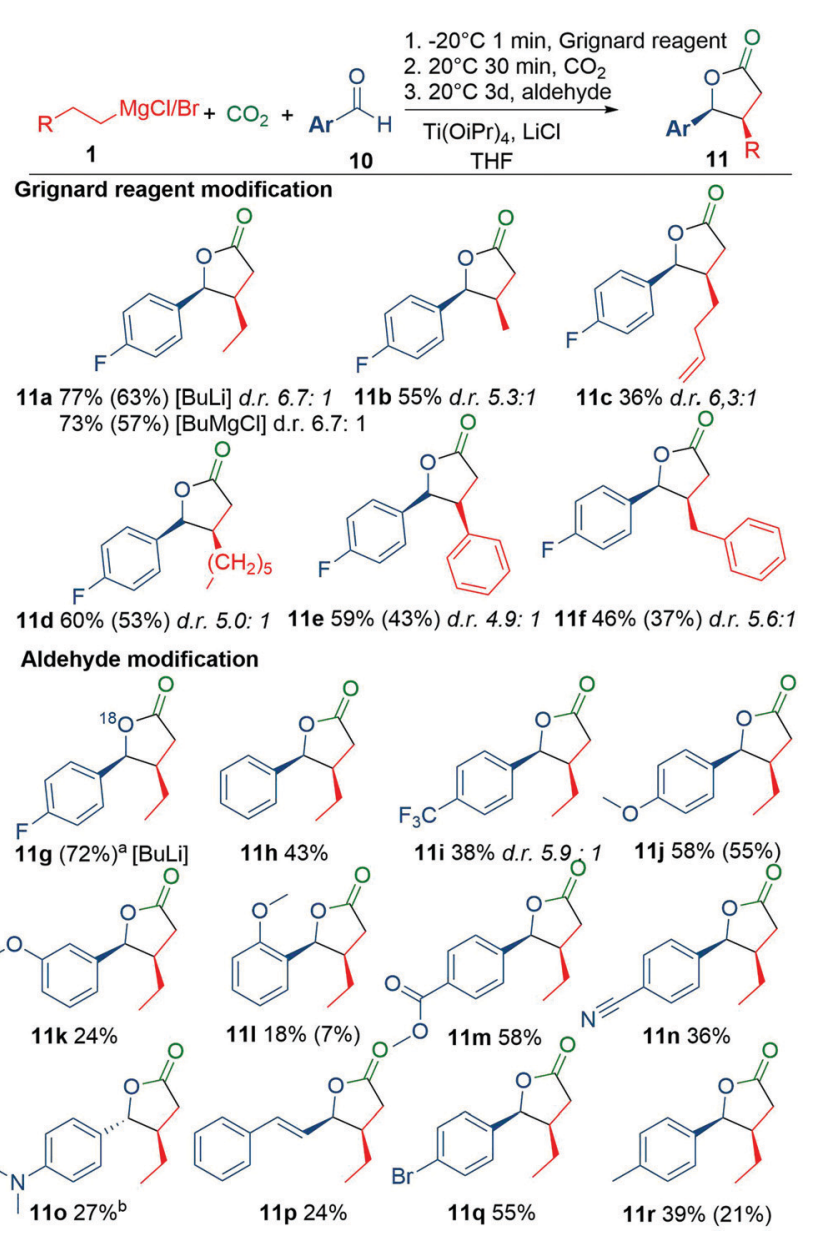

Scheme 2 Lactone formation from a variety of Grignard reagents and aldehydes. Yield is single cis-diastereomer yield measured by ${ }^{1} \mathrm{H}-\mathrm{NMR}$ with 1,3,5-trimethoxybenzene as internal standard. Isolated yield for the cisdiastereomer is in brackets. Stoichiometry is $2.6 \mathrm{mmol} \mathrm{BuMgCl}, 2.6 \mathrm{mmol}$ $\mathrm{LiCl}, 1.3 \mathrm{mmol} \mathrm{Ti}(\mathrm{OiPr})_{4}, 1 \mathrm{mmol}$ aldehyde, $3 \mathrm{ml}$ of THF. ${ }^{a} 69 \%{ }^{18} \mathrm{O}$-content starting from $76 \%{ }^{18} \mathrm{O}$ - $p$-fluorobenzaldehyde. ${ }^{b}$ trans-Diastereomer yield, which is the major product. 
With benzaldehydes (Scheme 2), the reaction tolerates a variety of common functionalities with both electron donating (11j $p$-OMe 58\%) and electron withdrawing (11m $p$-COOMe $58 \%$, 11q Br 55\%) properties. Note that ester $11 \mathrm{~m}$ and nitrile 11n can potentially react with organometallic reagents, but are tolerated here. However, the reaction has a strong dependence on the substitution pattern, where $m$-MeO (11k 24\%) and $o$-MeO (11l 18\%) yield less product than $p$-MeO (11j). The aldehydes are completely consumed in the reaction and the variation in yield is explained by selectivity between aldehyde insertion to the titanalactone or side reactions, such as pinacol coupling. The cis-diastereomer is the favoured product with a 7-5:1 ratio, although accurate determination could only be done for fluorinated compounds with ${ }^{19} \mathrm{~F}-\mathrm{NMR}$, due to overlapping impurities in ${ }^{1} \mathrm{H}$ for the trans-diastereomer. An exception to this selectivity was 110, where the trans-diastereomer was the major product. However, when BuLi was used to make $11020 \%$ trans and $21 \%$ cis crude was obtained. The crude quickly isomerises to $>10: 1$ trans-diastereomer on silica (see ESI $\dagger$ for details). This isomerization behaviour was not detected for any other lactones. The ${ }^{18} \mathrm{O}$ labelled $\mathbf{1 1 g}$ shows that the oxygen in the structure originates from the benzaldehyde.

In the Kulinkovich type reactions, it has been shown that if a primary alkene or alkyne is added to the mixture, the reaction will exchange the Grignard reagent with the added unsaturated compound. ${ }^{4 a, 9}$ Therefore, we investigated primary alkenes in our reaction. ${ }^{10}$ When $\mathrm{c}-\mathrm{HexMgCl}$ was used as the Grignard reagent, we could incorporate 1-hexene to yield $34 \%$ of cis-lactone after optimization (Scheme 3). Cyclic Grignard reagents are preferred, since they form a less stable titanacyclopropane, which facilitates the exchange with the primary alkene (Tables S7-8 and Fig. S11, ESI $\dagger$ ). Primary Grignard reagents and Buli produce a mixture of the exchanged and non-exchanged product (Table S8, ESI $\dagger$ ). Around 30\% yield could be obtained for several alkenes (Scheme 3), however vinyl butyl ether and styrene did not produce any lactone. This is likely due to the polarization of the double bond. Gratifyingly, the reaction tolerated trimethyl silyl and alkyl bromide groups, which were difficult substrates in the primary alkyl Grignard reagent version of this reaction (Scheme 2).

The mechanistic details of the transformation of dialkyltitanium to titanacyclopropane $\mathbf{3}$ have recently been investigated computationally by Bertus (Fig. S8, ESI $\dagger$ ). ${ }^{11}$ We have here employed DFT methods to investigate the reaction of titanacyclopropane 3a (Fig. S9, ESI $\dagger$ ) with $\mathrm{CO}_{2}$, and the subsequent benzaldehyde insertion leading to the formation of 3,4substituted butyrolactones (see ESI $\dagger$ for detailed protocol).

At the preferred inner sphere transition state for $\mathrm{CO}_{2}$ insertion into $3 \mathbf{a}\left(\mathbf{T S}_{\mathbf{A B}}\right.$, Fig. 1), the terminal carbon of butene performs a nucleophilic attack on the $\mathrm{CO}_{2}$ carbon, with a barrier of only $2.2 \mathrm{kcal} \mathrm{mol}^{-1}$ relative to A (Fig. 2, $298 \mathrm{~K}$ ). Attack of the internal butene carbon has a slightly higher barrier $\left(2.8 \mathrm{kcal} \mathrm{mol}^{-1}\right)$. The barrier for an alternative outer sphere $\mathrm{CO}_{2}$ insertion is $24.8 \mathrm{kcal} \mathrm{mol}^{-1}$ (298 K, Fig. S10, ESI $\dagger$ ), demonstrating that the inner sphere $\mathrm{CO}_{2}$ insertion is strongly preferred. Similar results have been obtained for the Kulinkovich reaction, where the first insertion

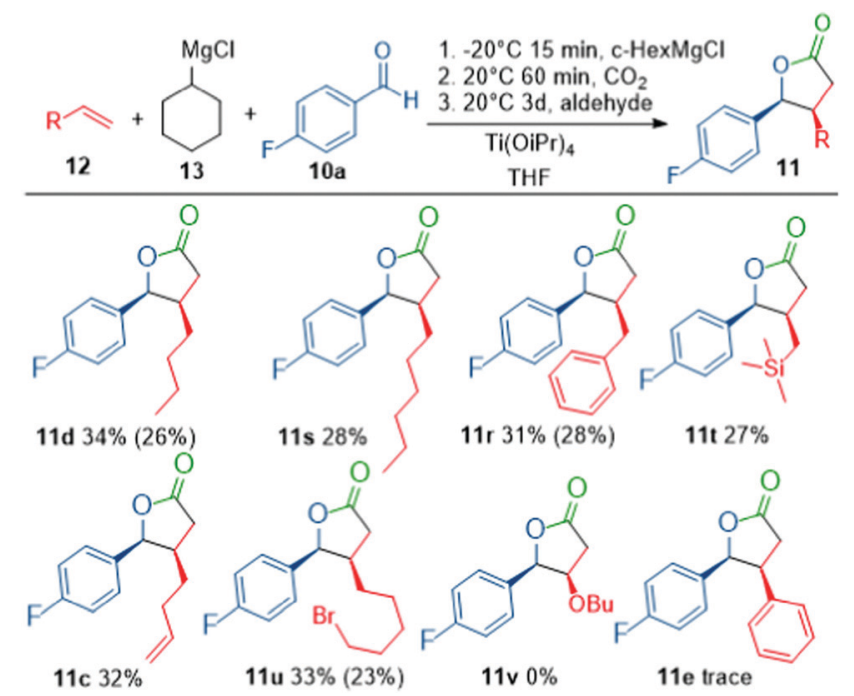

Scheme 3 Lactone formation from alkenes. Yield is single cisdiastereomer yield measured by ${ }^{1} \mathrm{H}$-NMR with 1,3,5-trimethoxybenzene as internal standard, isolated yield is in brackets. Stoichiometry is $4 \mathrm{~mol}$ alkene, $2.6 \mathrm{mmol} c-\mathrm{HexMgCl}, 1.3 \mathrm{mmol} \mathrm{Ti}(\mathrm{OiPr})_{4}, 1 \mathrm{mmol} p$ fluorobenzaldehyde, $3 \mathrm{ml}$ of THF.

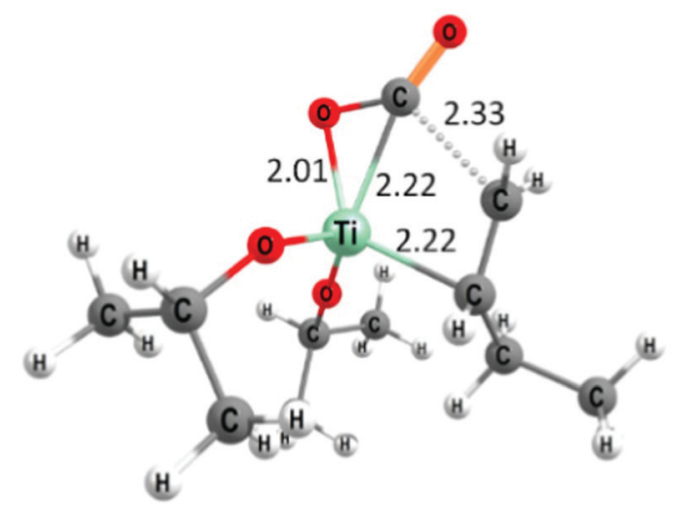

Fig. 1 Preferred inner-sphere transition state geometry for insertion of $\mathrm{CO}_{2}$ into 3 (TS $\left.\mathrm{AB}_{\mathrm{B}}, \mathrm{B} 3 \mathrm{LYP}-\mathrm{D} 3 / 6-31+\mathrm{G}(\mathrm{d}, \mathrm{p}), \mathrm{CPCM}[\mathrm{THF}]\right)$.

of ester proceeds through a low-barrier inner sphere pathway. ${ }^{12}$ The carboxylation barrier computed here is lower than what may be expected from the reaction time $\left(30\right.$ minutes warmed from $-20{ }^{\circ} \mathrm{C}$ to $20{ }^{\circ} \mathrm{C}$ ), however, we speculate that the increased reaction time is needed to decompose reactive organometallic species that would compete to consume the aldehyde in the next step.

The transformation of titanalactone $\mathbf{B}$ to butyrolactones starts with the coordination of 4-fluorobenzaldehyde to form C, which has a distorted trigonal bipyramidal geometry, with the aldehyde trans to the Ti-C bond. The alternative cis geometry $\mathbf{D}$ is $3.8 \mathrm{kcal} \mathrm{mol}^{-1}$ less stable $(298 \mathrm{~K})$, but it needs to be formed to allow for subsequent aldehyde insertion via $\mathbf{T S}_{\mathbf{D E}}$ (Fig. 2). $\mathbf{T S}_{\mathbf{D E}}$ has two possible conformations, leading to either $\mathbf{E}_{(\text {trans })}$ or $\mathbf{E}_{(\text {cis })}$, with the latter being thermodynamically preferred. The experimentally observed 7:1 cis selectivity 


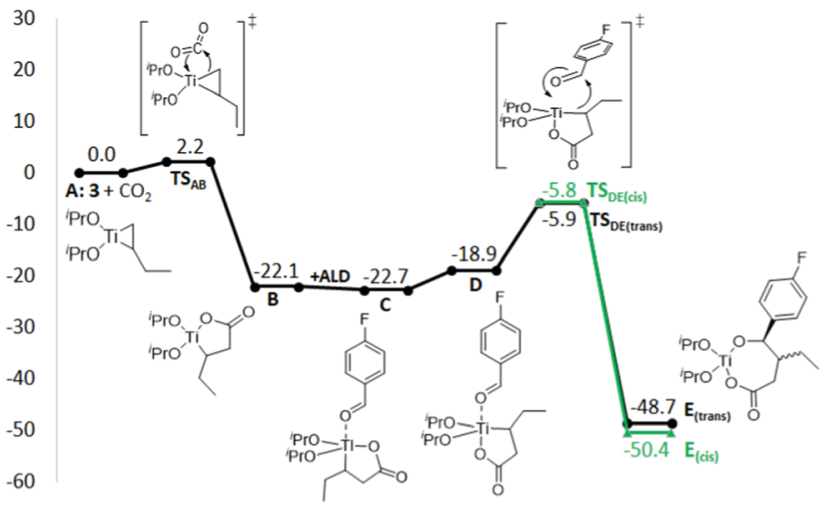

Fig. 2 Gibbs free energy profile for conversion of titanacyclopropane 3 to titanalactone $\mathbf{B}$, followed by aldehyde (ALD) insertion to form $\mathbf{E}$ (kcal mol ${ }^{-1}, 298 \mathrm{~K}$, B3LYP-D3/def2-TZVP,CPCM[THF]//B3LYP-D3/6$31+G(d, p), C P C M[T H F])$.

corresponds to $\mathrm{ca} .1 \mathrm{kcal} \mathrm{mol}^{-1}$ difference in energy barrier, which is within the error of the computational approach.

The computed barriers for insertion of acetophenone and phenylmethanimine into $\mathbf{B}$ are 20.9 and $28.6 \mathrm{kcal} \mathrm{mol}^{-1}$, respectively (Table S9, ESI $\dagger$ ), compared to $16.8 \mathrm{kcal} \mathrm{mol}^{-1}$ for 4-fluorobenzaldehyde (298 K). The higher barriers are due to a stronger binding of ketone and imine to titanium compared to the aldehyde and are in line with the experimentally observed lack of reactivity for the former two substrates, although the overall barrier for acetophenone indicates that some reactivity may have been expected.

Finally, we also studied the mechanistic details of the alkene exchange reaction (Scheme 3). Given that the direct decoordination of an alkene from species $\mathbf{A}$ is thermodynamically highly disfavoured (28.4 or $35.0 \mathrm{kcal} \mathrm{mol}^{-1}$ depending on the alkene, see Fig. S11 and S12, ESI $\dagger$ ), the reaction most likely proceeds through an associative mechanism involving formation of an intermediate, where both the alkene originating from the Grignard reagent (cyclohexene) and the added alkene (1-hexene) coordinate simultaneously (Fig. S11, ESI, $\dagger \mathbf{S 1 5}_{\mathbf{C y H e x}}$ ). After the alkene originating from the Grignard reagent decoordinates, a new species $\mathbf{A}$ is obtained, and the reaction follows the standard mechanism (Fig. 2). Calculations with cyclohexene as the original alkene and 1-hexene as the added alkene show a $9.9 \mathrm{kcal} \mathrm{mol}^{-1}$ barrier to decoordinate 1hexene from species $\mathbf{S 1 5}$ CyHex, compared to $2.3 \mathrm{kcal} \mathrm{mol}^{-1}$ for cyclohexene, which is in line with experimental results showing that an alkene exchange takes place under these conditions (Scheme 3, 11d). The exchange is driven by the greater stability for coordinating 1-hexene than cyclohexene $\left(-6.3 \mathrm{kcal} \mathrm{mol}^{-1}\right.$, Fig. S11, ESI $\dagger$ ). The analogous coordination of $\mathrm{CO}_{2}$ to species $\mathbf{A}$ was also calculated, and the obtained barrier $\left(16.7 \mathrm{kcal} \mathrm{mol}^{-1}\right)$ is much higher than that of the inner sphere insertion $\left(2.2 \mathrm{kcal} \mathrm{mol}^{-1}\right)$. This shows that $\mathrm{CO}_{2}$ will rather insert itself directly than first coordinate to species A (Fig. S13, ESI $\dagger$ ).

In summary, we have demonstrated a $\mathrm{CO}_{2}$-based method for the cis-selective synthesis of 3,4 butyrolactones using simple and easily available materials. The reaction forms two new carbon-carbon bonds in a three-component reaction, which makes it a powerful synthetic tool. While unstable titaniumintermediates limit the scope of substrates, this method can be useful to create a substitution pattern that usually requires several additional synthetic steps. The computational analysis indicates low stability of titanacyclopropane and a high stability of titanalactone. Coordination of an electrophile (e.g. aldehyde, imine, or ketone) leads to a low-energy intermediate, which determines the barrier of the final step. We foresee that the scope of the reaction might be expanded by changes to the steric and electronic properties of the initial titanium complex.

This work has been supported by CHEMS - The Doctoral Programme in Chemistry and Molecular Sciences at University of Helsinki, and the members of the Nordic Consortium for $\mathrm{CO} 2$ Conversion (NordCO2). KHH and DDC thank the Research Council of Norway (Grant No. 300769 and 262695), the Tromsø Research Foundation (Grant No. TFS2016KHH), NordForsk (Grant No. 85378) and Notur - The Norwegian Metacenter for Computational Science (No. nn9330k and nn4654k).

\section{Conflicts of interest}

There are no conflicts to declare.

\section{References}

1 (a) C. S. Yeung and V. M. Dong, J. Am. Chem. Soc., 2008, 130, 7826-7827; (b) T. Leon, A. Correa and R. Martin, J. Am. Chem. Soc., 2013, 135, 1221-1224; (c) Q. Liu, L. Wu, R. Jackstell and M. Beller, Nat. Commun., 2015, 6, 5933; (d) S.-S. Yan, Q. Fu, L.-L. Liao, G.-Q. Sun, J.-H. Ye, L. Gong, Y.-Z. Bo-Xue and D.-G. Yu, Coord. Chem. Rev., 2018, 374, 439-463; (e) S. Wang and C. Xi, Chem. Soc. Rev., 2019, 48, 382-404.

2 H. Gilman and R. H. Kirby, Org. Synth., 1925, 5, 75.

3 (a) O. G. Kulinkovich, A. I. Savchenko, S. V. Sviridov and D. A. Vasilevski, Mendeleev Commun., 1993, 3, 230-231; (b) A. de Meijere, C. M. Williams, A. Kourdioukov, S. V. Sviridov, V. Chaplinski, M. Kordes, A. I. Savchenko, C. Stratmann and M. Noltemeyer, Chem. - Eur. J., 2002, 8, 3789-3801; (c) O. G. Kulinkovich, S. V. Sviridov, D. A. Vasilevskii and T. S. Pritytskaya, Zh. Org. Khim., 1989, 25, 2244-2245.

4 (a) F. Sato, H. Urabe and S. Okamoto, Chem. Rev., 2000, 100, 2835-2886; (b) A. Wolan and Y. Six, Tetrahedron, 2010, 66, 15-61; (c) V. A. Rassadin and Y. Six, Tetrahedron, 2014, 70, 787-794.

5 (a) V. K. Chenniappan and R. J. Rahaim, Org. Lett., 2016, 18, 5090-5093; (b) P. Shao, S. Wang, C. Chen and C. Xi, Org. Lett., 2016, 18, 2050-2053; (c) F. Cadoret, P. Retailleau and Y. Six, Tetrahedron Lett., 2006, 47, 7749-7753; (d) O. L. Epstein, J. M. Seo, N. Masalov and J. K. Cha, Org. Lett., 2005, 7, 2105-2108; (e) F. Sato and S. Okamoto, Adv. Synth. Catal., 2001, 343, 759-784.

6 (a) M. McLaughlin, M. Takahashi and G. C. Micalizio, Angew. Chem., Int. Ed., 2007, 46, 3912-3914; (b) Y. Gao, M. Shirai and F. Sato, Tetrahedron Lett., 1997, 38, 6849-6852.

7 J. J. Eisch, J. N. Gitua, P. O. Otieno and X. Shi, J. Organomet. Chem., 2001, 624, 229-238.

8 (a) A. Krasovskiy and P. Knochel, Angew. Chem., Int. Ed., 2004, 43, 3333-3336; (b) R. L. Bao, R. Zhao and L. Shi, Chem. Commun., 2015, 51, 6884-6900.

9 (a) T. Nakagawa, A. Kasatkin and F. Sato, Tetrahedron Lett., 1995, 36, 3207-3210; (b) Y. Six, Eur. J. Org. Chem., 2003, 1157-1171.

10 John J. Eisch, Adetenu A. Adeosun and John N. Gitua, Eur. J. Org. Chem., 2003, 4721-4727.

11 P. Bertus, Organometallics, 2019, 38, 4171-4182.

12 Y. D. Wu and Z. X. Yu, J. Am. Chem. Soc., 2001, 123, 5777-5786. 